PRAXIS

ecucativa

Universidad Nacional de La Pampa

Facultad de Ciencias Humanas

Instituto de Ciencias de la Educación

para la investigación interdisciplinaria

\section{t 回潾 \\ Instituto de Ciencias de la Educación
para la Investigación Interdisciplinarit

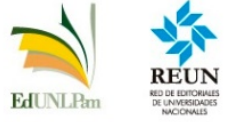

ISSN 2313-934X

SANTA ROSA, LA PAMPA, ARGENTINA

Correo electrónico: iceii@humanas.unlpam.edu.ar

Disponible en https://cerac.unlpam.edu.ar/index.php/praxis

Estrategias colaborativas: aprendizaje compartido para el desarrollo de la comprensión lectora en estudiantes de educación primaria Artículo de Leonel Alexander Menacho López. Praxis educativa, Vol. 25, No 3 septiembre - diciembre 2021. E - ISSN 2313-934X. pp. 1-16. https://dx.doi.org/10.19137/praxiseducativa-2021-250314

Esta obra se publica baja Licencia Creative Commons 4.0 Internacional

CC BY- NC- SA Atribución, No Comercial, Compartir igual

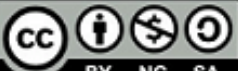

BY NC SA

\title{
Estrategias colaborativas: aprendizaje compartido para el desarrollo de la comprensión lectora en estudiantes de educación primaria
}

Collaborative strategies: shared learning for the development of reading comprehension in primary school students

Estratégias colaborativas: aprendizagem compartilhada para o desenvolvimento da compreensão leitora nos estudantes de ensino fundamental

\section{Leonel Alexander Menacho López}

Universidad Nacional Santiago Antunez de Mayolo (UNASAM), Huaraz, Perú

leonel20menacho@gmail.com

ORCID 0000-0001-5442-857X

Recibido: 2021-06-19 | Revisado: 2021-08-08 | Aceptado: 2021-08-17 


\section{Resumen}

El trabajo colaborativo influye positivamente en el aprendizaje de los educandos cuando es utilizado como estrategia para maximizar la participación e implicación de los estudiantes en los contenidos y actividades por desarrollar. Por consiguiente, el objetivo de la presente investigación fue identificar el aprendizaje compartido como estrategia colaborativa para mejorar la comprensión lectora de los estudiantes de Educación Primaria. Estudio cuantitativo de diseño preexperimental con dos grupos, cuya muestra estuvo conformada por 46 estudiantes de cuarto grado de Educación Primaria. Los resultados muestran que el 66,7 \% de los estudiantes previo a la intervención presentaron puntajes bajos; sin embargo, luego de la aplicación con las estrategias colaborativas, el 58,3 \% paso a obtener un puntaje regular y el $25 \%$ alcanzó un alto puntaje en el nivel literal de comprensión lectora. En conclusión, el aprendizaje compartido como estrategia colaborativa influye positivamente en la comprensión lectora de los estudiantes de Educación Primaria.

Palabras clave: estrategias educativas, aprendizaje, lectura, estrategias de aprendizaje, comprensión de lectura.

\section{Abstract}

Collaborative work has a positive influence on student learning when it is used as a strategy to maximize the participation and involvement of students in the contents and activities to be developed. Therefore, the objective of this research was to identify shared learning as a collaborative strategy to improve reading comprehension of Primary Education students. Quantitative study of pre-experimental design with two groups, whose population and sample consisted of 46 students in the fourth grade of Primary Education. The results show that $66.7 \%$ of the students prior to the intervention presented low scores, however, after the application with the collaborative strategies, $58.3 \%$ went on to obtain a regular score and $25 \%$ reached a high score on the literal level of reading comprehension. In conclusion, shared learning as a collaborative strategy positively influences the reading comprehension of Primary Education students.

Keywords: educational strategies; learning; reading; learning strategies; reading comprehension.

\section{Resumo}

O trabalho colaborativo influencia positivamente a aprendizagem dos alunos quando é utilizado como estratégia para maximizar a participação e envolvimento dos alunos nos conteúdos e atividades a desenvolver. Portanto, o objetivo desta pesquisa foi identificar a aprendizagem compartilhada como estratégia colaborativa para melhorar a compreensão leitora de alunos do Ensino Fundamental. Estudo quantitativo de delineamento pré-experimental com duas turmas, cuja população e amostra foi constituída por 46 alunos da quarta série do Ensino Fundamental. Os resultados mostram que 66,7\% dos alunos antes da intervenção apresentavam notas baixas, porém, após a aplicação com as estratégias colaborativas, 58,3\% passaram a obter nota regular e 25\% atingiram nota alta. Pontuação no nível literal de compreensão de leitura. Em conclusão, a aprendizagem compartilhada como estratégia colaborativa influencia positivamente a compreensão de leitura de alunos do Ensino Fundamental.

Palavras-chave: estratégias educacionais; aprendizagem; leitura; estratégias de aprendizagem; compreensão de leitura. 


\section{Introducción}

Las proyecciones de la Organización para la Cooperación y Desarrollo Económico señalan que los sistemas educativos, en el mundo, padecerán grandes trasformaciones durante los próximos diez años (OCDE, 2018). Por consiguiente, las formas de explicar y desarrollar la clase irán cambiando en concepción y metodología, pasando de enfoques educativos individualistas a enfoques más novedosos basados en el aprendizaje compartido, práctica educativa que, en las últimas décadas, se ha llevado a cabo con gran éxito (Azorín-Abellán, 2018; González y Salcines, 2019). Ello se debe a que los procesos de formación cada vez se tornan más libres, dinámicos y sociales porque entran en juego teorías sobre el aprendizaje colaborativo, como las propuestas por autores como Piaget o Vygotsky desde el plano psicológico, o se hace uso de teorías como las planteadas por Freinet o Dewey desde el plano pedagógico (Peñalva y Leiva, 2019).

En consecuencia, los cambios metodológicos permiten alcanzar las competencias generales que todo estudiante debe tener según el nivel donde se encuentra o al que aspira alcanzar. A partir de las estrategias colaborativas, el educando puede adquirir aprendizajes individuales y grupales mediante el trabajo en equipo, la continua realimentación y la comunicación entre parejas, intercambiando y confrontado ideas y opiniones de manera organizada, sin perder la motivación, la secuencia y el desarrollo de sus ideas sobre un tema de interés (Fonseca et al., 2019). Es apremiante que los docentes tomen decisiones en cuanto a la adaptación o aplicación de estrategias en función de las necesidades e intereses de los estudiantes; por lo que las decisiones metodológicas deberán responder a la diversidad de necesidades de los educandos (Del Valle et al., 2018).

La asociación de diferentes metodologías empleadas por los docentes para mejorar la comprensión lectora tiende a afectar positivamente en el rendimiento de la lectura de los aprendices. Por ello, se torna prudente implementar estrategias motivantes e innovadoras (Frende et al., 2017; Pulgar et al., 2018) a fin de cubrir las necesidades de los alumnos y favorecer su desempeño en la comprensión literal de la lectura.

Debido a las interacciones que suscitan y la diversidad de visiones que ponen en juego, las estrategias colaborativas suponen mejores beneficios tanto para alumnos como para los profesores porque permiten avanzar hacia un aprendizaje profundo y crítico, haciendo que el conocimiento significativo pase a ser una especie de conciencia compartida en la que todos aprenden de todos mediante la transformación de la práctica educativa. Por consiguiente, estas se han convertido en un elemento educativo imprescindible en las aulas de clase (Álvarez y Vejo, 2017; Peñalva y Leiva, 2019). Al respecto, el docente, en su hacer pedagógico, puede apropiarse de variadas herramientas metodológicas para sacarle ventaja al proceso de enseñanza y aprendizaje, sobre todo en el área de comunicación, área que busca desarrollar, en los educandos, la lectura, la comprensión de textos y las habilidades comunicativas tanto orales como escritas.

La lectura es una habilidad que se desarrolla a lo largo de la escolaridad, dado que, durante el nivel primario, se adquiere progresivamente la capacidad de comprensión lectora y, luego, esta se fortalece en la secundaria. Ello permite que el estudiante logre y consolide competencias en el 
manejo de la información y en la organización del aprendizaje significativo según las disciplinas (Blasco-Serrano et al., 2019; Fonseca et al., 2019; Gutiérrez et al., 2015; Romero et al., 2008; Romero, 2020).

La comprensión lectora es el objetivo fundamental de la lectura, proceso mental que realiza el estudiante para construir un significado propio sobre la base del contenido de un texto leído (Fonseca et al., 2019). En consecuencia, la lectura comprensiva cumple una tarea relevante en la vida del escolar, debido a que es una actividad cognitiva compleja que posibilita nuevos aprendizajes, además de constituirse en una capacidad necesaria para que el individuo pueda comunicarse de manera óptima con las demás personas (Figueroa y Gallego, 2018).

Lamentablemente, la problemática de la comprensión lectora ha venido en aumento pese a los avances logrados en el área de la comunicación. Al respecto, Larios et al. (2018) señalan que "si los estudiantes no son capaces de comprender lo que leen, mucho menos podrán desarrollar una postura frente a lo mismo, por lo que es necesario desarrollar la comprensión lectora para ayudar a un entendimiento integral de los textos" (p. 303). Según los autores antes mencionados, es evidente la desarticulación que existe entre los propósitos del curso y el área por desarrollar; por tanto, se debe seguir insistiendo en el uso de herramientas que posibiliten el desarrollo de la comprensión lectora.

Es importante señalar que, en todas las instituciones educativas de Perú, se ha implementado el Programa para la Evaluación Internacional de Estudiantes (PISA). Sin embargo, en la última prueba de comprensión lectora realizada en 2018, de 77 naciones que participaron, Perú solo alcanzo a posicionarse en el puesto 64 según la OECD (2018). Asimismo, el Ministerio de Educación (MINEDU), a través de sus procesos para promover la calidad de la educación, aplicó, durante ese mismo año, la Evaluación Censal de Estudiantes (ECE), prueba que tiene como propósito informar sobre los resultados de los aprendizajes obtenidos por los alumnos, detallando logros y limitaciones, a fin de adoptar las medidas correctivas que permitan mejorar el proceso educativo. Esta prueba mostró resultados poco alentadores, reflejando, por ejemplo, que los estudiantes de educación primaria en la Región Áncash (región donde se ubica el colegio Macashca-Huaraz, en el que se llevó a cabo la investigación) presentaron un logro parcial de los aprendizajes esperados. Los resultados de las pruebas muestran que solo el $26,1 \%$ de los alumnos alcanzaron un nivel satisfactorio, mientras que el 32,9\% todavía se encuentra en proceso de aprendizaje, en tanto que el $28,5 \%$ se ubica en el nivel elemental (poseen aprendizajes muy restringidos), y el 12,5 \% se halla en la categoría previo al inicio, es decir, no tiene los aprendizajes necesarios para su clase escolar.

Los resultados de la prueba de Pisa no son solo números, más bien son números a tener en cuenta por el Estado peruano para evaluar el nivel de desarrollo de la educación de nuestro país. Por su parte, los resultados de la ECE en la Región Áncash han demostrado que el área de comunicación no ha sido trabajada de manera apropiada, por cuanto son evidentes las carencias presentadas por los estudiantes con respecto al nivel literal de comprensión lectora. A pesar de las capacitaciones realizadas por el Ministerio de Educación, algunos docentes continúan con la idea errónea de que leer es decodificar. Asimismo, persiste la falta de planificación de las sesiones de 
aprendizaje y la aplicación de estrategias pocos colaborativas; en consecuencia, la comprensión lectora se ha constituido en una de las limitaciones encontradas en las actividades diarias en el aula de Educación Primaria.

\section{Estrategias colaborativas}

Las estrategias son definidas por Revelo et al. (2018) como "el conjunto de herramientas, recursos, instrumentos y actividades necesarias para el alcance de los objetivos" (p. 12) y la toma de decisiones. Por su parte, las estrategias colaborativas como una herramienta didáctica conducen a conceptualizar las diversas formas de abordar el conocimiento empleado por los docentes para garantizar el aprendizaje de los educandos. No obstante, tal variedad de abordajes es expuesta de manera particular por cada docente durante la clase.

Las estrategias de aprendizaje colaborativo se centran en la interactividad entre estudiantes-estudiantes y docente-estudiantes, dado que estos actores educativos comparten sus ideas, conocimientos, valores y hasta sentimientos aprendiendo de otros, de forma organizada y estructurada, por lo que las estrategias colaborativas pueden también llamarse interactivas. Las estrategias colaborativas contribuyen a comprender y respetar las visiones de los demás, fortaleciendo el comportamiento y pensamiento autónomo, haciendo que el estudiante sea más independiente y busque soluciones ya sea individual o colectivamente.

Al emplear estrategias colaborativas, se induce a que el estudiante lea el material para la clase, participe y construya conceptos y desarrolle habilidades sociales con la ayuda del docente. En este sentido, las estrategias colaborativas permiten el desarrollo de la capacidad para trabajar en equipo: los alumnos aprenden más rápido puesto se esfuerzan más que cuando están solos; además, tienden a ampliar su vocabulario (Peñalva y Leiva, 2019).

Las estrategias colaborativas tienen su propia metodología de enseñanza, por ejemplo: 1) el docente describe cada una de las actividades y acciones por desarrollar, mediante instrucciones orales, invita a los alumnos a leer una guía o simplemente a través de un video; 2) aplica las estrategias tomando como ejemplo distintas situaciones; 3) se aplica la práctica guiada cuyas actividades posibilitan el apoyo y ayuda de todos los estudiantes para ser completadas; y, por último, 4) el docente realiza una realimentación de las actividades prácticas, mediante las cuales los estudiantes ejecutaron y resolvieron sus tareas y actividades sin la ayuda de sus compañeros o docente.

El aprendizaje colaborativo, como resultado del trabajo colaborativo, se sustenta en el constructivismo (Revelo-Sánchez, 2018) por cuanto es un proceso en el que se aprende, a través de la interacción de los miembros del equipo, más de lo que aprenderían por sí mismos, siempre que sus miembros sean capaces de distinguir y contrastar sus puntos de vista, provocando así un proceso de construcción de conocimiento. Por consiguiente, el aprendizaje se construye a través de procesos sociales, donde se involucran e interactúan constantemente los actores del hecho socioeducativo; por tanto, el docente proporciona autoridad al grupo, y cada uno de sus miembros ejecuta funciones y tareas otorgadas de común acuerdo (Zarzar, 2016). 
En consecuencia, las estrategias colaborativas deben estar alineadas a la enseñanza de tal manera que se reconozcan y se expliquen los procesos cognitivos y metacognitivos que los estudiantes han utilizado durante la acción pedagógica.

\section{Comprensión lectora}

La comprensión de un texto tiene que ver con la capacidad de entender y discernir lo que se está leyendo, con el objeto de obtener un significado, bien sea para quien lo lee como para quien lo haya escrito. En este sentido, el lector se acerca a lo que piensa y experimenta el autor. Por consiguiente, la comprensión lectora es el resultado de la integración entre el texto y el lector que cambia o amplía la información según sus objetivos, intereses, conocimientos previos o táctica lectora. La comprensión lectora es la capacidad que se tiene para entender y comprender globalmente el significado de las palabras dentro de una estructura textual (Gispert y Rivas, 2010; Cuñachi y Leyva, 2018).

Según Cuñachi y Leyva (2018), la comprensión lectora estimula el desarrollo cognoscitivo. Por tanto, el docente debe actualizar sus competencias profesionales, adquiriendo nuevos recursos, técnicas y estrategias que faciliten el proceso de aprendizaje en los estudiantes, buscando el apego, el amor y gusto hacia la lectura, que les permitirá reflexionar de manera coherente sobre la realidad actual. No obstante, para comprender correctamente un texto, es necesario que el lector conozca las características de las diversas estructuras textuales, dado que se relaciona, se involucra con el texto, en una comunicación en la que se movilizan las destrezas de pensamiento.

La habilidad de relacionarse y conectarse con lo que se lee tiende a convertirse en una capacidad para el acceso al conocimiento, debido a la cuantiosa información que se encuentra en registros y relatos escritos. Comprender lo que se lee permite al lector alcanzar conocimientos cada vez más indefinidos y complejos, favoreciendo con ello la adquisición de nuevos aprendizajes (Gutiérrez et al., 2015). Sin embargo, poder comprender un texto requiere conocer la estructura textual, asumir las etapas de percepción, decodificación, retención y evocación; comprender un texto exige ir más allá de las palabras, es recrear los sentidos, es construir significados en la vida de quien lee. Pese a que la comprensión lectora es una habilidad humana sumamente compleja, se ha logrado un consenso al distinguir sus niveles (Castillo-López y Jiménez-Fernández, 2016): literal, inferencial, crítico (Gallego-Ortega et al., 2019; Smith, 1989) y metacomprensivo.

El nivel literal hace referencia a la capacidad del alumno para entender claramente lo que dice el texto, ya que permite identificar y recordar sucesos, según la secuencia de acciones.

A nivel inferencial, el lector puede hacer suposiciones e hipótesis sobre un texto leído; por consiguiente, requiere de procesos superiores, como la interpretación, el análisis y la generalización, para resolver problemas e incluso implica deducir información que no aparece de forma explícita en el texto. El nivel crítico refiere a la capacidad que tiene de evaluar la calidad del texto y expresar juicios razonados sobre el mismo, rechazando o aceptado la posición de quien escribe. En el nivel de metacomprensión lectora, se pueden detectar errores en la comprensión, reconocer las causas 
que provocan el error y aplicar estrategias correctivas (Castillo-López y Jiménez-Fernández, 2016; Vallés-Arándiga y Vallés-Tortosa, 2006).

Dada la importancia de comprender que la lectura es una habilidad necesaria para el desarrollo educativo y social del escolar, el presente artículo tuvo como objeto de investigación identificar el aprendizaje compartido como estrategia colaborativa para mejorar la comprensión lectora de los estudiantes de Educación Primaria.

\section{Metodología}

Se implementa un estudio cuantitativo de diseño prexperimental -sin grupo control- en dos grupos. Investigación de campo, que permitió identificar el aprendizaje compartido como estrategia colaborativa para mejorar la comprensión lectora de los estudiantes de Educación Primaria. Estudio que se llevó a cabo en el colegio nacional Macashca-Huaraz, en la Región Áncash de Perú. La muestra estuvo conformada por 46 alumnos de cuarto grado de la Institución Educativa № 86007, cuya selección se efectuó mediante muestreo por conveniencia, bajo el criterio de proximidad con los estudiantes como unidad de análisis procedentes de dos secciones diferentes, que luego conformaron los dos grupos, un grupo A constituido por 22 alumnos y un grupo B, por 24 alumnos, con la misma proporción de mujeres y varones. A ambos grupos, se les aplicó una prueba de comprensión lectora elaborada ad hoc, administrada en dos momentos (pre-y postest), es decir, previo a la intervención y luego de esta con las estrategias colaborativas implementadas durante cuatro semanas en el aula de clases. Para evaluar su validez, se utilizó el juicio de expertos, con tres especialistas en lectura, escritura y didáctica, a quienes se les hizo llegar una escala de estimación cualitativa en cuanto a claridad, ambigüedad, tendenciosidad y pertinencia. La prueba consistió en cinco textos de literatura infantil, de longitud breve, pero de diferente organización textual, que fueron presentados a los alumnos según el proceso por desarrollar: comparación/contraste, descripción, secuencia temporal, causa/efecto y problema/solución. Tras cada texto, los alumnos respondían dos preguntas de opción múltiple, una de nivel literal y otra de nivel inferencial.

Este estudio se propuso promover la comprensión lectora mediante estrategias colaborativas en los estudiantes de cuarto grado de Educación Primaria, por la debilidad que presentaban estos alumnos en el nivel literal. Las estrategias colaborativas consideradas fueron: Lectura Compartida, Construcción oral a partir de imágenes, Animación y Juego "Parafraseando".

Las técnicas de análisis utilizadas fueron: la estadística descriptiva para el procesamiento de los datos y el análisis inferencial para establecer la influencia de las estrategias colaborativas en la comprensión lectora. Los resultados fueron presentados en tablas y se analizaron mediante la prueba T de Student. 


\section{Descripción de las actividades}

Inicialmente, se les propuso a los alumnos conformar libremente equipos de cinco participantes como máximo. Una vez conformados los equipos, se procedió a dar las instrucciones generales relacionadas con el tiempo y las normas para llevar a cabo cada una de las siguientes actividades.

En la primera sesión de clase (45 minutos), se hizo uso de la Lectura Compartida como estrategia colaborativa; para ello, se instó a los estudiantes a interpretar y expresar lo que dicen los textos seleccionados previamente por el docente, o se los invita a asumir el rol de sujeto y lector de manera sincronizada, en un tiempo no mayor a 20 minutos. Una vez realizada la lectura del texto por parte de los alumnos, estos deberán manifestar su punto de vista en torno a los contenidos presentados en el texto, dejando manifiesta su perspectiva de logros y dificultades en torno a lo leído. Finalmente, sobre la base de las interpretaciones de los estudiantes, el docente interviene a fin de facilitar el intercambio de ideas entre los alumnos y construir una interpretación más precisa de lo leído.

En la segunda sesión de clase (45 minutos), se utilizó la estrategia Construcción oral a partir de imágenes porque, a través de esta estrategia, el docente puede planificar intervenciones ajustadas a los grupos que se ubican en niveles similares. Para esta actividad, se recomendó a los equipos hacer una lectura conjunta según la imagen sugerida por el docente, enfatizándoles que debían formular de manera grupal un texto en referencia a la imagen y una frase incompleta; para ello, se les presentaron cuatro frases, por lo que la selección debía producirse en un corto tiempo. Cabe destacar que tres de las opciones son falsas, dos son pseudopalabras que constituyen pares mínimos ortográficos y fonológicos de la respuesta correcta y la tercera es inadecuada para completar la frase desde el punto de vista semántico y sintáctico. Una vez finalizada la actividad grupal, el docente procederá a precisar sobre estos aspectos antes de dar por culminada la actividad de clase.

En la tercera sesión de clase (45 minutos), se usó la Animación a través de la técnica de cuenta cuento; dado que el alumno tiende a convertirse en centro de su propio aprendizaje, durante esta sesión, se invitó a los estudiantes a relatar un cuento en voz alta, pero debían darle sentido y significado a lo que leían (conforme iban leyendo) mientras otro de los miembros del equipo procedía a grabar un vídeo de ello. Esto con la finalidad de reproducir entre sí la experiencia y proceder a valorar la experiencia de animación lectora en cuanto al dominio de aspectos comunicacionales, verbales y no verbales. Ello porque las reflexiones metacognitivas de las experiencias de animación lectora tienden a verse positivamente como una estrategia didáctica eficaz para mediar el acercamiento del alumno a la lectura.

En la cuarta sesión de clase (45 minutos), se trabajó con el Juego "Parafraseando", porque es un método útil para la comprensión de información compleja. En el parafraseo, el lector introduce o narra la información con sus propias palabras a fin de facilitar la retención y conexión con la proposiciones previas o posteriores. Como método de evaluación, muestra objetivamente las diferencias entre los alumnos. En este sentido, se procedió a dar las instrucciones para el desarrollo 
de la actividad. Luego, se le hizo entrega a uno de los miembros del equipo de diversos textos cortos y se les solicitó que seleccionaran uno según su preferencia e interés; luego, se los indujo a expresar las ideas principales en referencia al texto leído, detallándolas con sus propias palabras. Una vez culminada la actividad por parte de los equipos, se les proporcionó una retroalimentación para garantizar el éxito en la actividad realizada.

Finalmente, un miembro de cada uno de los equipos de trabajo escribió en el pizarrón sus precisiones como equipo en torno a las actividades desarrolladas durante las cuatro sesiones de clase desarrolladas.

\section{Resultados}

Los resultados se categorizaron según los siguientes puntajes: 2 (muy bajo), 4 (bajo), 6 (regular), 8 (alto) y 10 (muy alto). El puntaje más alto obtenido, tanto en el pretest como en el postest, fue de 8. Los niveles de logro, según la Evaluación Censal de Estudiantes (ECE), posibilitan la descripción de logro no solo en términos numéricos, sino en términos de aprendizaje (MINEDU, 2016). Los datos obtenidos tanto del grupo A como del grupo B, en el nivel literal de comprensión lectora y en estrategias colaborativas para la mejora de la compresión lectora, reflejan lo siguiente:

\section{Tabla 1}

Puntajes obtenidos en el pretest y en el postest en el nivel literal de la comprensión lectora por estudiantes del Grupo A

\begin{tabular}{|c|c|c|c|c|}
\hline \multirow{2}{*}{ Puntaje } & \multicolumn{2}{|c|}{ Pretest } & \multicolumn{2}{|c|}{ Postest } \\
\hline & Frecuencias & $\%$ & Frecuencias & $\%$ \\
\hline 2 & 2 & 9.1 & 1 & 4.5 \\
\hline 4 & 12 & 54.5 & 6 & 27.3 \\
\hline 6 & 8 & 36.4 & 14 & 63.6 \\
\hline 8 & 0 & 0.0 & 1 & 4.5 \\
\hline TOTAL & 22 & 100.0 & 22 & 100.0 \\
\hline Media & \multicolumn{2}{|c|}{4.55} & \multicolumn{2}{|c|}{5.36} \\
\hline D.E. & \multicolumn{2}{|c|}{1.26} & \multicolumn{2}{|c|}{1.29} \\
\hline
\end{tabular}

Los puntajes obtenidos en el pretest muestran que el 63,6 \% de los estudiantes que conforman el Grupo A alcanzaron un puntaje bajo de 4 puntos en el nivel de comprensión lectora. En cambio, en el postest, se advierte un cambio significativo al reflejar, en un 63,6 \%, un puntaje regular, esto es, una mejora en la comprensión literal. Luego, se puedo demostrar que las estrategias colaborativas son efectivas al ser aplicadas a los alumnos, ya que mejoran su nivel de comprensión. 


\section{Tabla 2}

Prueba T Student de los puntajes obtenidos en el nivel literal de la comprensión lectora por los estudiantes del Grupo A

\begin{tabular}{cccccc}
\hline \multirow{2}{*}{$\begin{array}{c}\text { Pretest y } \\
\text { postest }\end{array}$} & \multicolumn{2}{c}{ Diferencias Relacionadas } & \multicolumn{3}{c}{ Prueba T para igualdad de medias } \\
\cline { 2 - 6 } & Media & Desv. Estándar & $\mathbf{t}$ & Gl & Valor $\mathbf{p}$ \\
\hline Grupo A & 0.818 & 1.006 & 3.813 & 21 & 0.001 \\
\hline
\end{tabular}

En el Grupo A, la diferencia de medias entre el pretest $(M=4.64)$ y el postest $(M=5,36)$, en la prueba $T$ de Student para muestras relacionadas, arroja un valor de 0.818, $p=0.001$; ello indica que se verifican diferencias estadísticamente significativas. Por ende, podemos concluir que ha habido cambios positivos en el Grupo A.

\section{Tabla 3}

Puntajes obtenidos en el pre- y postest en el nivel literal de la comprensión lectora por los estudiantes del Grupo B

\begin{tabular}{ccccc}
\hline \multirow{2}{*}{ Puntaje } & \multicolumn{2}{c}{ Pretest } & \multicolumn{2}{c}{ Postest } \\
\cline { 2 - 5 } & Frecuencias & $\mathbf{\%}$ & Frecuencias & $\mathbf{\%}$ \\
\hline 2 & 2 & 8.3 & 0 & 0.0 \\
4 & 16 & 66.7 & 4 & 16.7 \\
6 & 5 & 20.8 & 14 & 58.3 \\
8 & 1 & 4.2 & 6 & 25.0 \\
\hline TOTAL & $\mathbf{2 4}$ & $\mathbf{1 0 0 . 0}$ & $\mathbf{2 4}$ & $\mathbf{1 0 0 . 0}$ \\
\hline Media & \multicolumn{2}{|c}{6.17} \\
\hline D.E. & \multicolumn{2}{|c}{1.31}
\end{tabular}

Los resultados del pretest muestran que el $75 \%$ de los estudiantes que conforman el Grupo B manifiestan un puntaje bajo (2 o 4 puntos) de comprensión lectora. Sin embargo, en el postest, el $83 \%$ de los estudiantes alcanzó un puntaje entre regular (6) y alto (8), lo que significa una mejora significativa en el nivel literal de comprensión lectora a través de las estrategias colaborativas. 


\section{Tabla 4}

Prueba TStudent de los puntajes obtenidos en el nivel literal de la comprensión lectora de los estudiantes del Grupo B

\begin{tabular}{ccccccc}
\hline \multirow{2}{*}{ Pretest y postest } & \multicolumn{2}{c}{ Diferencias Relacionadas } & \multicolumn{3}{c}{ Prueba T para igualdad de medias } \\
\cline { 2 - 6 } & Media & Desv. Estándar & $\mathbf{t}$ & Gl & Valor $\mathbf{p}$ \\
\hline Grupo B & 1.75 & 1.48 & 5.786 & 23 & 0.000 \\
\hline
\end{tabular}

La prueba T Student mostró que, en el Grupo B, la diferencia de medias es de 1.75 y el valor de $p=0.000$, esto es, diferencias estadísticamente significativas. Pareciera que las estrategias colaborativas Lectura Compartida, Construcción oral a partir de imágenes, Animación y Juego "Parafraseando"influyen positivamente en el nivel literal de la comprensión lectora.

\section{Tabla 5}

Estrategias colaborativas en el postest en el nivel literal alto de la comprensión lectora de los estudiantes de los grupos $A$ y $B$

\begin{tabular}{ccccc}
\hline $\begin{array}{c}\text { Estrategias } \\
\text { Colaborativas }\end{array}$ & $\begin{array}{c}\text { Grupo A } \\
\text { Frecuencias }\end{array}$ & $\mathbf{\%}$ & $\begin{array}{c}\text { Grupo B } \\
\text { Frecuencias }\end{array}$ & $\mathbf{\%}$ \\
\hline Lectura Compartida & 6 & 27,27 & 4 & 16,5 \\
$\begin{array}{c}\text { Construcción oral a } \\
\text { partir de imágenes }\end{array}$ & 2 & 9,09 & 4 & 16,5 \\
Animación & 8 & 36,36 & 6 & 25 \\
Juego Parafraseando & 6 & 27,27 & 10 & 42 \\
\hline TotaL & $\mathbf{2 2}$ & $\mathbf{1 0 0 . 0}$ & $\mathbf{2 4}$ & $\mathbf{1 0 0 . 0}$ \\
\hline Media/Promedio & $5,5 / 24,99$ & \multicolumn{2}{c}{$6 / 25$} \\
\hline
\end{tabular}

La relación entre la comprensión lectora de los estudiantes encuestados pertenecientes a los grupos A y B y la frecuencia de las estrategias colaborativas obtenida a partir de los datos se evaluó según la siguiente escala de puntuación: de 0 a 25, Deficiente; 25 a 50, Bajo; 50 a 75, Regular; y, finalmente, de 75 a 100, Alto. En relación con los puntajes obtenidos luego de la aplicación de las estrategias colaborativas, el Grupo A mostró que Animación obtuvo un porcentaje del 36,36 \%, mientras que la Lectura Compartiday el Juego "Parafraseando" obtuvieron un porcentaje de 27,27 \%. En cambio, en Construcción oral a partir de imágenes, el desempeño es bajo. Tres de las cuatro estrategias colaborativas permitieron mejorar el nivel de comprensión lectora en el Grupo A. El 
Grupo B reflejó un 25 \% en Animación mientras que, en el Juego "Parafraseando", mostró un 42 \%. Las restantes estrategias alcanzan porcentajes más bajos. No obstante, los resultados del Grupo B también muestran que las estrategias colaborativas facilitan y estimulan no solo la lectura, sino que también mejoran la comprensión lectora del nivel literal.

\section{Discusión de los resultados}

La finalidad principal de la investigación fue promover la comprensión lectora a través de las estrategias colaborativas Lectura Compartida, Construcción oral a partir de imágenes, Animación y Juego "Parafraseando" en los estudiantes de cuarto grado de Educación Primaria del Colegio Nacional Macashca-Huaraz, en la Región Áncash de Perú, por la debilidad que estos alumnos presentaban en el nivel literal de comprensión lectora. Vista la alarmante situación del nivel de comprensión lectora observado en los puntajes obtenidos en el pretest de ambos grupos, se requirió prestar la debida atención sobre las variables estratégicas que, probablemente, tienden a influir en el rendimiento de esta área, considerando que el docente, en su quehacer pedagógico, decide qué estrategia implementar para que sus estudiantes desarrollen habilidades y competencias lectoras en atención a lo que quiera trabajar o lograr (Revelo et al., 2018).

Los porcentajes obtenidos luego de la aplicación de las estrategias colaborativas Lectura Compartida, Construcción oral a partir de imágenes, Animación y Juego "Parafraseando" demuestran que este tipo de estrategias son necesarias para que el alumno desarrolle un nivel de comprensión lectora adecuada. Resultados coincidentes con lo señalado por Calvo (2019), quien sostiene que la Lectura Compartida es un espacio acogedor para los estudiantes, que les ayuda a desarrollar actitudes hacia la cultura escrita. Asimismo, García (2019) señala que la Construcción oral a partir de imágenes consiste en analizar elementos más sencillos para después abordar los más complejos, por lo que la habilidad de decodificar es muy importante para entender y procesar los textos. Por su parte, Jumbo y Mendieta (2019) consideran que la Animación es una estrategia o actividad para la mejora de comprensión lectora, porque no solo influye sustancialmente en el desarrollo de procesos psíquicos, sino también en el despliegue de la fantasía y creatividad. Finalmente, Guillén y Maldonado (2019) afirman que la estrategia de parafraseo (Juego "Parafraseando") permite a los estudiantes expresar con sus propias palabras lo que comprendieron después de que leyeron el texto, dado que el parafraseo induce al lector a contarse a sí mismo el relato.

Una vez identificadas las estrategias colaborativas por utilizar, se mostró la relación entre estas y el nivel de comprensión lectora alcanzado por los alumnos integrantes de la muestra. El $54,5 \%$ de los estudiantes del Grupo A presentó un bajo puntaje en el pretest para el nivel de comprensión lectora, mientras que, en el postest, este mismo grupo obtuvo un 63,6 \%, mostrando un cambio significativo con un puntaje regular. Por lo tanto, se logró una mejora significativa en la comprensión lectora. De manera similar, el 66,7 \% de los estudiantes que conformaron el Grupo B 
presentó, en el pretest, un puntaje bajo para el nivel de comprensión lectora, mientras que, después de aplicar las estrategias colaborativas (postest), evidenciaron un cambio significativo, observándose que el 58,3\% de los estudiantes reflejaron un puntaje regular y un $25 \%$ de los estudiantes de este grupo logró el nivel alto en la comprensión lectora. En síntesis, la aplicación de las estrategias colaborativas en el Grupo A muestra que Animación permitió mejorar la comprensión lectora y que, a su vez, las estrategias Animación y Juego "Parafraseando"la mejoran en el Grupo B, resultados que demostraron que las estrategias colaborativas facilitan y estimulan no solo la lectura, sino la comprensión lectora del nivel literal (Castillo-López y Jiménez-Fernández, 2016).

En ambos grupos, la diferencia de medias entre el pre- y el postest alcanza significatividad estadística. Esto comprueba que existen diferencias estadísticamente significativas: las estrategias colaborativas Lectura Compartida, Animación, Construcción oral a partir de imágenes y Juego "Parafraseando" han influido positivamente en el nivel literal de la comprensión lectora de los alumnos de cuarto grado de Educación Primaria del Colegio Nacional Macashca-Huaraz. Resultados que coinciden con lo informado por Esquivel et al. (2018), quienes señalan que las estrategias colaborativas favorecen la comprensión lectora de los educandos, además de incentivar la participación activa. En efecto, interactuar y compartir la lectura en equipo proporciona ideas claras y valores que elevan la motivación lectora del alumno (Álvarez y Vejo, 2017).

Sin embargo, es importante acotar que un estudio realizado por Gallego Ortega et al. (2018) reveló que, a medida que los estudiantes avanzan de curso, el nivel de competencia lectora decrece, motivado presuntamente por la despreocupación por la lectura en los niveles de educación superiores y por el incremento en la complejidad léxica de los textos. En consecuencia, la comprensión lectora demanda mayor atención y dedicación por parte del profesorado en los niveles inicial y básico.

\section{Conclusiones}

La construcción de un espacio de aprendizaje a través de estrategias colaborativas es crucial para el desarrollo de la comprensión lectora porque, a través de la intervención, se genera una interacción fluida entre pares, estudiantes-estudiantes y docente-estudiantes. Durante la intervención, se pudieron diferenciar claramente los procesos de comprensión en los dos momentos de pre- y postest, gracias a una serie de estrategias que propiciaron la participación y el recurso a los conocimientos previos, promoviendo cambios en la lectura y en la advertencia sobre cómo se encontraban organizadas las ideas. Mediante las estrategias, los estudiantes construyeron colectivamente significados de muchas palabras.

Las pruebas estadísticas mostraron que la aplicación de las estrategias colaborativas influyó en la mejora de la comprensión lectora del nivel literal de los educandos, dado que, en el postest, los alumnos lograron identificar y recordar sucesos, dándole secuencia a las acciones, identificando, asociando y ordenando las ideas con un sentido completo. 
En conclusión, las estrategias colaborativas contribuyen a mejorar la comprensión lectora por cuanto tienden a maximizar la comunicación del educando a través de la apropiación de un vocabulario amplio y fluido, permitiéndole el desarrollo y el fortalecimiento de la comprensión lectora.

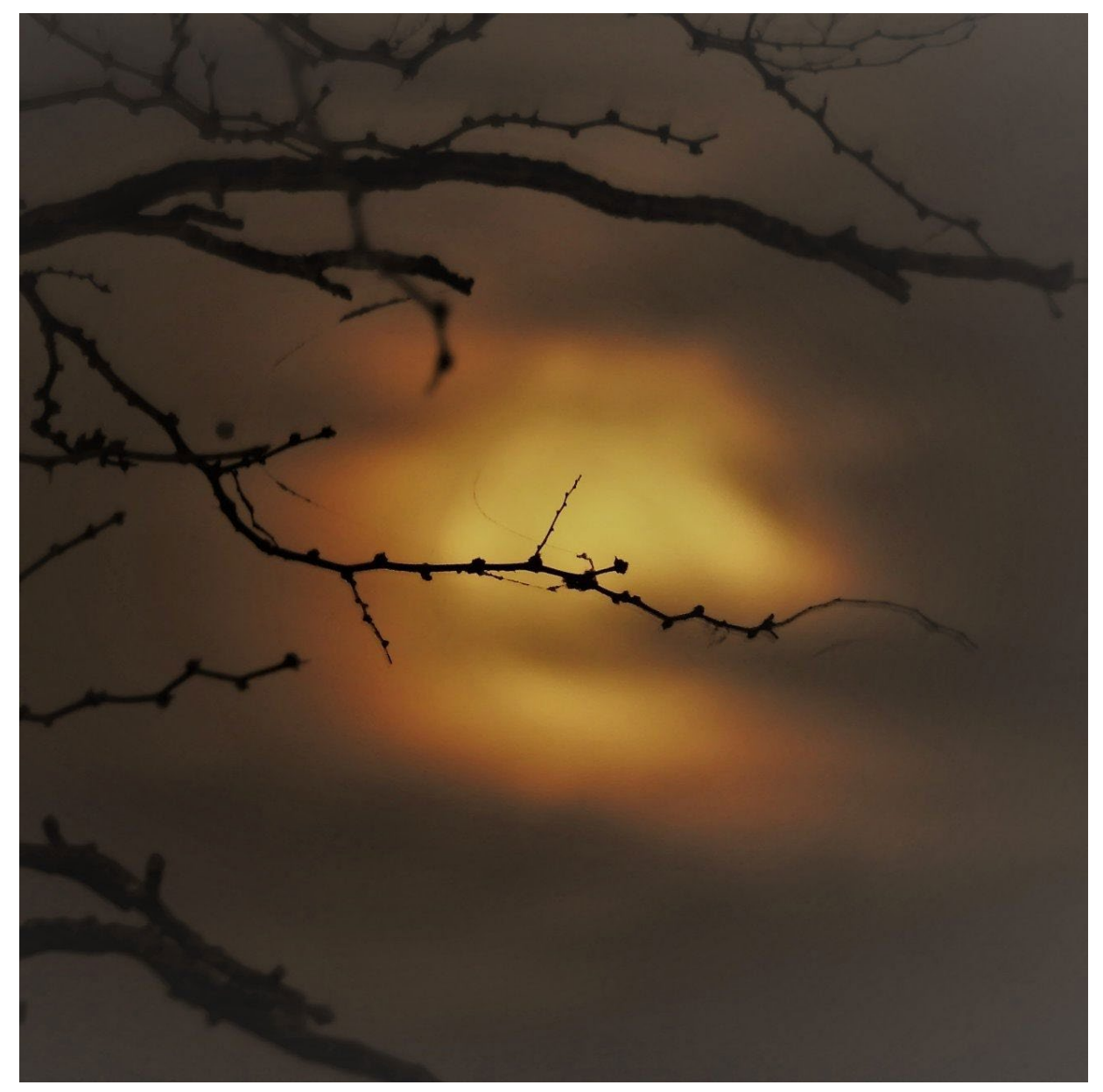

Sin título, fotografía. Andrea Talone

\section{Bibliografía}

Álvarez, C. y R. Vejo (2017). Mejora de la competencia literaria con un club de lectura escolar. Bliblios, (68), 110122. https://dx.doi.org/10.5195/biblios.2017.351

Azorín-Abellán, C. (2018). El método de aprendizaje cooperativo y su aplicación en las aulas. Perfiles Educativos, 40(161), 181-194. https://doi.org/10.22201/iisue.24486167e.2018.161.58622

Blasco-Serrano, A. C., Pérez, A. A. y Laparte, M. Á. (2019). Claves de la mediación para el desarrollo de la comprensión lectora. Un estudio cualitativo en aulas de $4^{\circ}$ de educación primaria. REOP-Revista Española de Orientación y Psicopedagogía, 30(2), 9-27. https://doi.org/10.5944/reop.vol.30.num.2.2019.25335

Calvo, V. (2019). El diario de lectura en los procesos de acogida de familias inmigrantes. Ocnos, 18(1), 41-51. https://dx.doi.org/10.18239/ocnos_2019.18.1.1789 
Castillo López, A. V. y Jiménez Fernández, G. (2016). ¿Es adecuado el enfoque de los libros de texto para el desarrollo de la comprensión lectora ?: Análisis crítico de materiales de Educación Primaria. Opción, 32(7), 437454. https://www.redalyc.org/articulo.oa?id=31048480024

Cuñachi, G. y Leyva, G. (2018). Comprensión lectora y el aprendizaje en el área de Comunicación Integral en los estudiantes de Educación Básica Alternativa de las instituciones educativas del distrito de Chaclacayo UCEL O6 Ate Vitarte año 2015 (Tesis de pregrado). Universidad Nacional de Educación Enrique Guzmán y Valle, Perú. http://repositorio.une.edu.pe/bitstream/handle/UNE/1335/TESIS\%2OCOMPRENSION\%2OLECTORA.pdf?sequ ence=1\&isAllowed $=y$

Del Valle, S., Rodríguez, J., De Cisneros, J., Cabanillas, E. y Castillo, I. (2018). Educación ¿qué cambios se pretenden? Indivisa. Boletin de Estudios e Investigación, (18), 39-63. https://www.redalyc.org/pdf/771/77153913002.pdf Esquivel, P., Villa, F., Guerra, G., Guerra, C. y Rangel, E. (2018). El aprendizaje colaborativo como estrategia didáctica para el mejoramiento de la Comprensión lectora. Cultura, educación y sociedad, 9(3), 105-112. http://hdl.handle.net/11323/2114

Frende, M. A., Biedma, J. M. y Arana, M. (2017). Influencia de la Percepción y Metodologías docentes aplicadas en el rendimiento académico de los estudiantes de la asignatura de dirección de Recursos Humanos en las empresas turísticas. Cuadernos de Turismo, (39), 149-166. http://dx.doi.org/10.6018/turismo.39.290481

Figueroa, S. y Gallego, J. L. (2018). Vocabulario y comprensión lectora en escolares chilenos de primer ciclo básico. Ocnos, 1711), 32-42. https://doi.org/10.18239/ocnos_2018.17.1.1521

Fonseca, L., Migliardo, G., Simian, M., Olmos, R. y León, J. (2019). Estrategias para Mejorar la Comprensión Lectora: Impacto de un Programa de Intervención. Psicología Educativa, 25(2), 91-99. https://doi.org/10.5093/psed2019a1

Gallego Ortega, J. L., Figueroa Sepúlveda, S. y Rodríguez Fuentes, A. (2019). La comprensión lectora de escolares de educación básica. Literatura y lingüística, (40), 187-208. https://dx.doi.org/10.29344/0717621x.40.2066

García, M. (2019). Programas de entrenamiento de comprensión lectora en educación primaria (Tesis de pregrado). Universidad de Jaén, España. http://tauja.ujaen.es/jspui/handle/10953.1/10279

Gispert, D. y Rivas, L. (2010). Alumnado con dificultades en el aprendizaje de la lectura. Graó.

Conzález, N. y Salcines, I. (2019). Aprendizaje Cooperativo híbrido y su evaluación formativa y compartida en el grado de educación infantil. una buena práctica en la universidad de Cantabria. Infanciá, Educación y Aprendizaje (IEYA), 5(2), 34-39. https://dialnet.unirioja.es/servlet/articulo?codigo=7319689

Guillén, S. y Maldonado, V. (2019). Desarrollo de estrategias cognitivas para mejorar la comprensión lectora del idioma inglés. CienciAmérica, 8(2), 189-201. http://dx.doi.org/10.33210/ca.v8i2.241

Gutiérrez, H., Aguiar, M. y Díaz, L. (2015). Contexto escolar y comprensión lectora en la prueba ENLACE en bachilleratos de Jalisco. CPU-e,Revista de Investigación Educativa, 20(1), 1-24. https://www.researchgate.net/publication/277721098_Contexto_escolar_y_comprension_lectora_en_la_pr ueba_ENLACE_en_bachilleratos_de_Jalisco

Jumbo, G. N. y Mendieta, J. E. (2019). Plan de actividades de animación para el mejoramiento de la comprensión lectora en Educación Básica. Polo de/ Conocimiento, 4(8), 298-316. http://dx.doi.org/10.23857/pc.v4i8.1182 MINEDU (2016). Marco de fundamentación de las pruebas de la Evaluación Censal de Estudiantes. Ministerio de Educación del Perú. http://umc.minedu.gob.pe/wp-content/uploads/2017/12/Marco-deFundamentaci\%C3\%B3n-ECE.pdf

Larios Gómez, A. E. (2018). Implementación de actividades basadas en la Comprensión Lectora como estrategia para el fortalecimiento de la lectura crítica. Cultura, educación y sociedad, 9(3), 303-308. https://doi.org/10.17981/cultedusoc.9.3.2018.34 
OCDE. (2018). The future of education and skills. Education 2030. https://www.oecd.org/education/2030/E2030\%20Position\%20Paper\%20(05.04.2018).pdf OECD. (2018). PISA test 2018. https://www.oecd.org/pisa/test/ Peñalva, A. y Leiva, J. J. (2019). Metodologías cooperativas y colaborativas en la formación del profesorado para la interculturalidad. Tendencias Pedagógicas, (33), 37-46. http://dx.doi.org/10.15366/tp2019.33.003 Pulgar, D., Bolaño, D., Martínez, D., De la Cruz, F., Rodríguez, J., Martínez, M., Meza, M. y Castillo, M. (2018). Lectura y comprensión lectora mediante las tecnologías de la información y comunicación en educación básica. Cultura, educación y sociedad, 9(3), 567-580. https://doi.org/10.17981/cultedusoc.9.3.2018.68

Revelo, 0., Collazos, C. A. y Jiménez, J. A. (2018). El trabajo colaborativo como estrategia didáctica para la enseñanza/aprendizaje de la programación: una revisión sistemática de literatura. TecnoLógicas, 27(41), 115134. http://www.scielo.org.co/pdf/teclo/v21n41/v21n41a08.pdf

Romero, R. M. (2020). Acciones pedagógicas para propiciar los pilares fundamentales de la educación venezolana. ¿Realidad o utopía? Revista San Gregorio, 1739), 87-101. http://revista.sangregorio.edu.ec/index.php/REVISTASANGREGORIO/article/view/1308

Romero, N., Romero, R., Zamudio, G. y Romero, B. (2008). Gestión contralora de Proyectos Educativos Integrales Comunitarios en Instituciones Educativas. Revista Venezolana de Gerencia, 13(42), 288-305. http://ve.scielo.org/scielo.php?pid=\$1315-99842008000200008\&script=sci_arttext\&tIng=pt Smith, C. B. (1989). La enseñanza de la lecto-escritura: un enfoque interactivo. Aprendizaje Visor. Vallés-Arándiga, A. y Vallés-Tortosa, C. (2006). Comprensión lectora y estudio. Intervención Psicopedagógica. Promolibro.

Zarzar, C. (2016). Instrumentación didáctica por competencias. Grupo Editorial Patria. 